\title{
Following nature, completing the cycle, properly utilizing our precious water - exploration of future urban water systems
}

\author{
Y. Feng ${ }^{1}$, R. Otterpohl ${ }^{2}$, K. Wichmann ${ }^{1} \&$ U. Braun ${ }^{2}$ \\ ${ }^{I}$ Institute of Water Resources and Water Supply, \\ Hamburg University of Technology, Germany \\ ${ }^{2}$ Institute of Wastewater Management and Water Protection, \\ Hamburg University of Technology, Germany
}

\begin{abstract}
Nowadays, fresh water is already one of the most critical issues for modern cities. However, we still manage and use the water in the traditional way which is unwisely and wasteful. Therefore, in this article the concepts of modern urban water systems are explored and demonstrated. First of all, water supply, wastewater disposal and rainwater discharge; three systems are planned and designed as one integrated urban water system (IUWS). Then, urban water end users are re-categorized followed by the depiction of special end users, such as landscape and waterscape, and so on. Possible system options are also discussed, like source separation collection, water reuse and multi-stage water utilization, etc. Afterwards, how to properly complete the water cycle within urban area is investigated, whereby new concepts are generated and demonstrated. Based on this concept, the interactions between city capacity and water capacity are discussed from the viewpoint of the city master planning in the end.
\end{abstract}

Keywords: integrated urban water systems (IUWS), city master planning, water cycle, water reuse, multi-stage water utilization.

\section{Introduction}

Conventionally, water supply, wastewater disposal and rainwater discharge systems are planned, constructed and operated as three independent systems. Water supply system is the unitary system with centralized waterworks supplying the unique water quality, i.e. drinking quality. After usage, the 
traditionally so-called wastewater from different end-uses is dumped into sewers and then drains to the wastewater treatment plant (WWTP). As for rainwater, because of its uneven distribution and unpredictable availability over time, normally rainwater is not considered as an urban water resource. On the contrary, rainwater tries to be released from the urban area as soon as possible due to its flood risks. As a result, giant rainwater drain systems are needed. These concepts of establishing urban water systems can be traced back to early Rome [1], and are still implemented today.

Conventional urban water systems have a couple of advantages, such as simple system structure, easy to operate and control, and very importantly, it has quite a lot of experience and successful examples from developed countries. However, these systems transfer most burdens directly to the environment. With today's severe situation, e.g. population explosion, worldwide urbanization and industrialization, etc., nature cannot afford us such a luxury system any more. Moreover, climate change is another serious and critical issue already in front of us. Thus, not only the developing areas, but also the developed areas are suffering water problems.

Therefore, after a thousand years' development, the urban water system is still the fresh issue as well as the critical challenge for us.

\section{Basic concept}

Figure 1: depicts the conventional and possible water pathways in urban area.

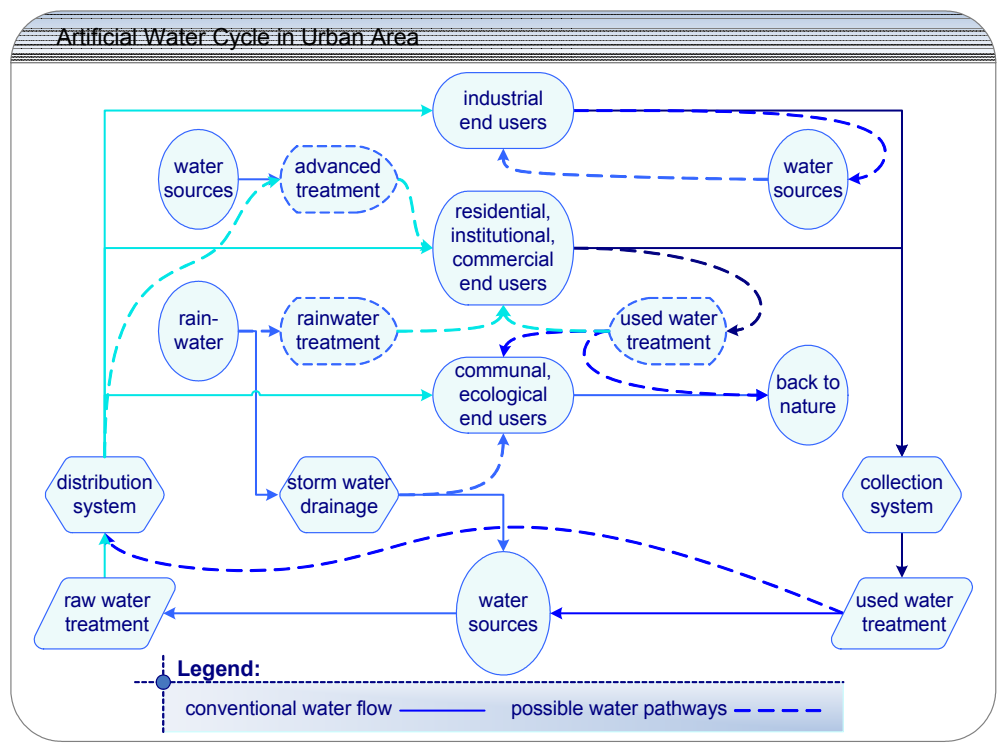

Figure 1: $\quad$ Artificial water cycle in urban area [2]. 
The figure clearly shows that three sub water systems are tightly related to each other, which means the urban water systems should be considered as one integrated system. It also reveals that the integrated urban water system (IUWS) should be the properly closed system, where water cycles take place spatially and temporally over the whole system.

In order to make the concept applicable, IUWS is subdivided into four layers classified into two types. Type one is AREA, including layer 1: Total City (TC) and layer 2: Urban District (UD). UD is the subset of TC. UD and TC have the same attributes and their water systems are planned according to their basic information, such as total area, population and gross domestic product, and so on. Type two is UNIT, which also includes two layers: Water Utilization Unit (WUU) and Water Utilization Cell (WUC). In general, WUU covers certain area with certain water end users, and its water system can be managed and coordinated within one organization. For example, it can be one university or two joined residential quarters. WUC has the same structure as WUU but in a small scale that mostly focuses on the indoor water system, especially for single or several adjacent buildings. If the essential information is adequate, the water system of WUU or WUC can be design in details.

Figure 2 demonstrates the hierarchy structure of IUWS with the layers. As multi water loops can take place simultaneously in all places, this hierarchy helps to plan the water systems in different scopes cooperatively and individually within IUWS.

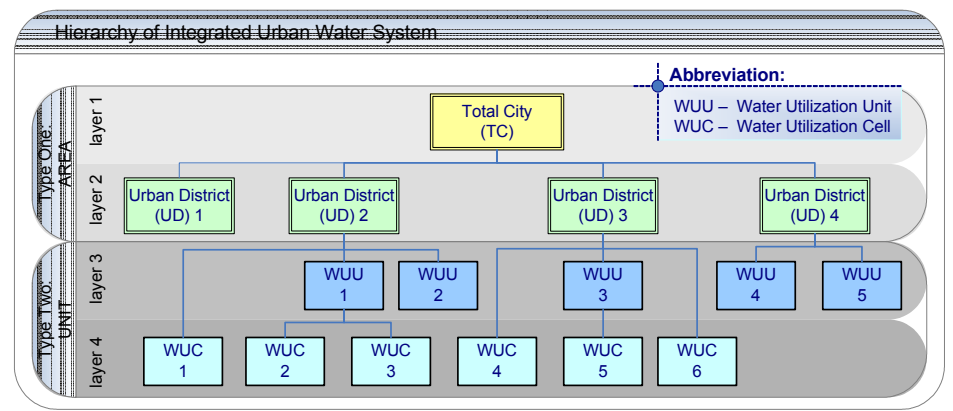

Figure 2: Demonstration of the hierarchy of IUWS.

In order to implement the concept of IUWS further, firstly the important components and possible system options have to be explained and discussed, and they are presented in the next sections.

\section{Essential components}

\subsection{Water sources}

It is classified into two types, i.e. local source and external source. Each unity in each layer can have either one or both of them. Because the layers are imbedded in each other, the local sources in a higher layer can be the external sources for 
the lower layer. The main advantage of classifying water sources in this way is that each unity can be dealt with as the independent one, so when many loops are together, the structure of the whole IUWS is still trenchant and ascertainable.

\subsection{Water quality}

Different end users have different quality requirements. Evidently, it is unwise and wasteful to flush our toilet and irrigate our gardens with drinking water. Therefore, in order to save treatment costs, as well as use water multi-times, the corresponding water quality standards need to be set up. In our IUWS the water quality is defined in three levels (table 1). Moreover, in terms of the different types of source water, i.e. raw water and used water, the water standards are further divided into two subsets (details in table 1, too).

Table 1: $\quad$ Categorization of treated water quality.

\begin{tabular}{|l|l|l|lr|}
\hline $\begin{array}{l}\text { source } \\
\text { water }\end{array}$ & level I & level II & level III \\
\hline raw water & drinking water & $\begin{array}{l}\text { non-potable, can } \\
\text { be contacted by } \\
\text { human }\end{array}$ & $\begin{array}{l}\text { restricted to be } \\
\text { contacted } \\
\text { human }\end{array}$ \\
\hline used water & non-direct potable & the same as above & the same as above \\
\hline
\end{tabular}

Traditionally, the wastewater system is also the unitary one, which mixes all used water from different end-uses together. According to the concept of ecological sanitation (ECOSAN), the more efficient way is to collect different sorts of wastewater, separately [3]. Hereby, two definitions are introduced: i.e. blackwater and graywater. Blackwater is the flush water from toilets, whereas graywater comes from household activities other than toilets. Figure 3 shows the characteristics of three sorts of water.

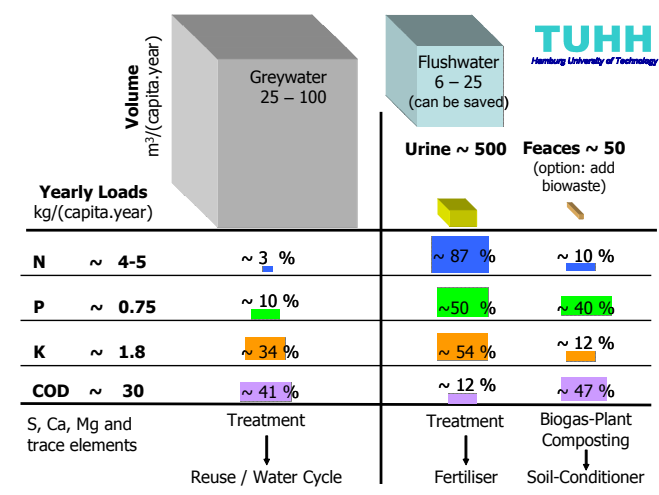

Figure 3: Characteristics of domestic wastewater with no dilution for faeces and urine [4]. 
Obviously, most nutrients and dangerous pathogens exist in blackwater, where graywater can be more easily used again after certain treatment. As the solid substances, the faeces should be isolated from our water system. At the same time, the treatment of faeces can be more efficient without mixing with plenty of water. Regarding urine, it is very good fertilizer that can be directly implemented to agriculture after a certain period of storage. Unfortunately, so far our society is still lacking in regulations and practical chains for utilizing our excrements, which also means that these cycles are still waiting to be closed.

\subsection{Urban water end users}

The city is the highly condensed area, besides essential life requirements, many other purposes also have to be fulfilled, such as industries, entertainment and ecosystems, and so forth. In order to allocate and utilize the limited water sources appropriately, the urban water end users are categorized into three sorts based on the concept of IUWS (table 2).

Table 2: $\quad$ Classification of water end users.

\begin{tabular}{|l|l|l|}
\hline sort & purpose & example of group end user \\
\hline $\begin{array}{l}\text { human beings } \\
\text { consumption }\end{array}$ & $\begin{array}{l}\text { meet the requirements of } \\
\text { human activities }\end{array}$ & $\begin{array}{l}\text { residential area, offices } \\
\text { building, commercial centre }\end{array}$ \\
\hline $\begin{array}{l}\text { communal \& } \\
\text { ecological usage }\end{array}$ & $\begin{array}{l}\text { maintain and improve the } \\
\text { urban living conditions, }\end{array}$ & $\begin{array}{l}\text { street washing, green belt, } \\
\text { landscape, waterscape, lakes }\end{array}$ \\
\hline Industrial usage & for industrial production & food, beverage, paper, etc. \\
\hline
\end{tabular}

The end users are treated as group users and correspond with WUU. The essential water usage profile of each group end user is thereby set up according to their quality and quantity features. Figure 4 gives an example of how to structure the water usage profile. It provides opportunities to balance the water inside WUU, so that the water usage of WUU can be optimized.

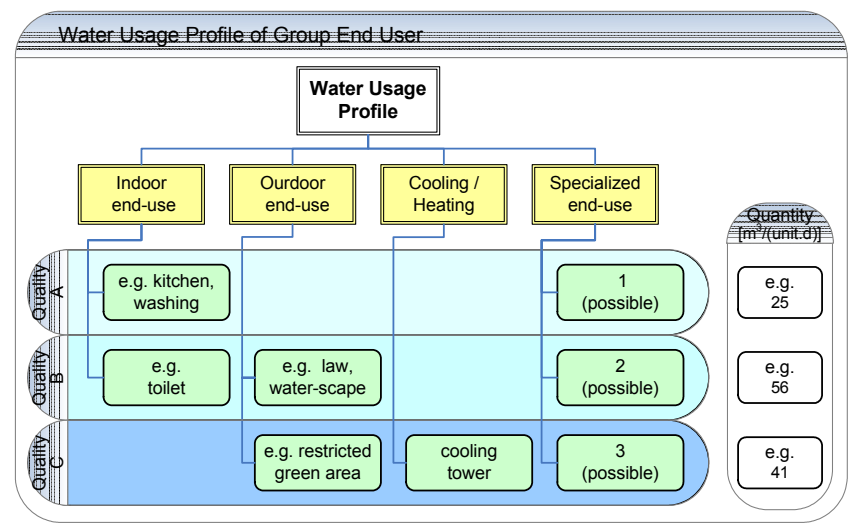

Figure 4: $\quad$ Structure of water usage profile. 
Communal and ecological water usage is increasingly earning attention in modern urban planning, so it is necessary to make a deeper explanation.

Landscape. One side landscape enhances the urban environmental quality and sequentially improves the urban living quality; on the other side, a huge amount water might be required for its maintenance. If the improper vegetation species as well as the unsuitable scale of landscapes are chosen, the landscape can become an oppressive burden to the urban water system.

Waterscape. Likewise, waterscape is another important ecological and social element in modern cities. In the same situation, its type and scale need to be set up prudently. Especially in the area that evaporation is much higher than precipitation, too much water might be consumed and consequently, waterscape will not be economic and affordable any more.

Lake and pond. They help to keep the urban environment healthy. Being environmental buffer systems, they modulate not only urban circumstance, but also storm water. The cycle of those water bodies need to be paid attention to, as the quality of the still system can decay rapidly.

\subsection{Treatment facilities}

Based on the construction methods, treatment facilities can be categorized into two types: field construction and package plant. Thanks to modern industries, today's package plants have many superiorities, such as flexible sizes, high treatment efficiency, simple operation and competitive prices etc., which provide more possibilities to construct urban water systems.

\subsection{Transportation system}

Besides the common transportation methods, i.e. pipe and channel systems, vehicles can be also the appropriate transportation method, especially for small amount material, e.g. blackwater and urine. As a very expensive but extremely low water consumption system, the earlier vacuum toilet was mainly used in special situations like airplanes and submarines, etc. Today it is more and more applied to the civil toilets and it is thereby a good option for evolving our urban water system.

\subsection{Water fixtures}

Finally let us focus on the water devices. To improve the efficiency of water fixtures is one of the most efficient and easiest ways to save our water. Thus, it should be always considered and performed in the first place.

\section{System options}

The options introduced below will help to close the urban water cycle properly. 


\subsection{Dual water supply}

Two separated pipe systems supply two kinds of water quality at the same time. It is designed for the situations where the source water is quantitatively enough but qualitatively scarce. Although it has been a mature idea for a long time, it is not widely implemented due to the high costs of doubled pipe systems. However, if the dual water system is considered within IUWS, it can be the better solution, typically when the water reuse system or/and rainwater utilization system are involved.

\subsection{Source separation collection}

As described before, collecting different sorts of wastewater separately is a more efficient way, where not only the water will be significantly saved, but also many materials can be properly utilized and even energy can be produced simultaneously. Particularly, a source separation collection system is the optimal system for middle and small-size water systems, as it makes the water cycle more able be closed locally, and at the same time large water mains are avoided.

\subsection{Water reuse}

As a quite broad concept, water reuse has been trialled for decades. Nonetheless, during its implementation many obstacles have come forth from our society especially in urban areas, mainly on account of cultural, religious and mental reasons. Therefore, the concept of multi-stage water utilization is introduced. The main difference between reuse and multi-stage utilization is that reclaimed water is supplied to the same end-uses again and sophisticated treatment processes are generally needed for reuse system.

\subsection{Multi-stage water utilization}

Different end-uses have different requirements of water quality which makes it possible to use water several times. For example, water from the washing basin can be directly used for flushing the toilet bowl; water from the shower and bath can be further used for watering gardens. Simple treatment might be needed in order to meet the required quality.

\subsection{Storm water management}

With pipe or canal systems to discharge storm water outside a city is one way to manage storm water; with a buffer system to retain storm water inside an urban area is another. Pipe/canal system is the normal way, which does not seem to be the ecological solution. Buffer systems provide adequate time for an urban area to assimilate the rainfall, which is the more natural way. At the same time, it turns the storm water into a potential water resource. The buffer system can be in many forms, such as lakes, ponds, wetland, and so on. 


\subsection{Rainwater utilization}

Rainwater itself is very clean and already distributed over space, so rainwater can be a very good urban water resource relying on rainfall patterns and properly designed utilization systems. Because of many man-made pollutants on the ground, in these systems the rainwater is mainly collected from roofs (called roofwater) and normally can reach very good quality after only simple treatment.

\section{Integrated urban water system (IUWS)}

Now the challenge is how to optimally organize and assemble those elements and options together in a certain case. Figure 5 demonstrates a detailed IUWS based on the system structure discussed above. As a step further, table 3 presents

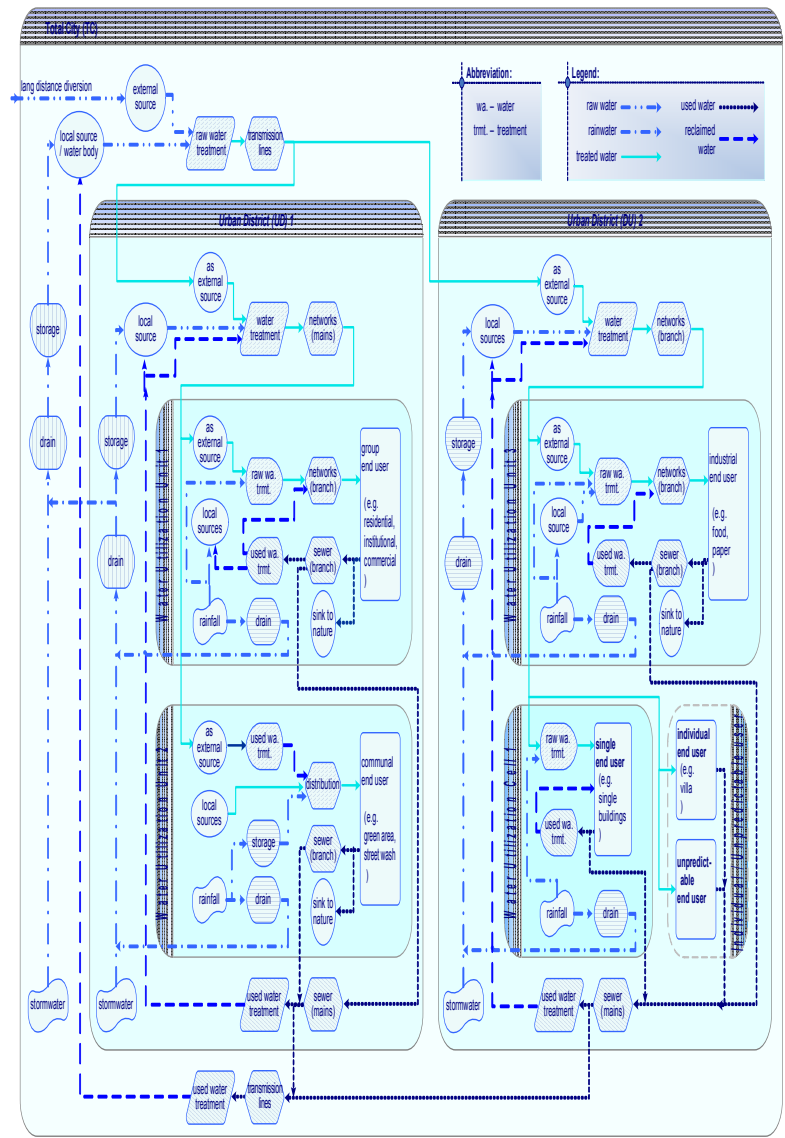

Figure 5: Demonstration of the detailed IUWS. 
the general design and optimization process of IUWS. As the water cycle can be closed in each layer, each block can work independently, so it is a versatile design process. Meanwhile, in reality not all necessary information is always available, so some steps in the process can also be skipped. For example, based on the states of WUU in the UD, the design of UD can be further divided into 3 scenarios: i. without information of WUU, ii. with basic information of WUU but no detailed design and iii. with detailed design of WUU. Subsequently, the corresponding steps will be adopted.

Table 3: $\quad$ Design and optimization process of IUWS.

\begin{tabular}{|c|c|c|c|c|}
\hline \multirow{2}{*}{\multicolumn{5}{|c|}{\begin{tabular}{l|l} 
step & $\mathrm{m}$ \\
\end{tabular}}} \\
\hline & & \\
\hline $\mathrm{a}$ & \multicolumn{4}{|c|}{$\begin{array}{l}\text { collect basic information, e.g.: planned area, population, districts, } \\
\text { etc. }\end{array}$} \\
\hline $\mathrm{b}$ & \multicolumn{4}{|c|}{$\begin{array}{l}\text { evaluate possible water sources, considering quality, amount and } \\
\text { location }\end{array}$} \\
\hline c & \multicolumn{4}{|c|}{$\begin{array}{l}\text { determine possible centralized waterworks and WWTP (location and } \\
\text { scale) }\end{array}$} \\
\hline & \multicolumn{4}{|c|}{ Urban District (UD) } \\
\hline & $\mathrm{d}$ & \multicolumn{3}{|c|}{ collect basic information of UD } \\
\hline & $\mathrm{e}$ & \multicolumn{3}{|c|}{ evaluate possible water sources, including rainfall ass } \\
\hline & $f$ & \multicolumn{3}{|c|}{ estimate water demands of UD (rough) } \\
\hline & $\mathrm{g}$ & \multicolumn{3}{|c|}{$\begin{array}{l}\text { determine proper water systems of UD (considering all system } \\
\text { options) }\end{array}$} \\
\hline & $\mathrm{h}$ & \multicolumn{3}{|c|}{ design storm water management system } \\
\hline & & \multicolumn{3}{|c|}{ Water Utilization Cell (WUU) } \\
\hline & & $\mathrm{i}$ & \multicolumn{2}{|r|}{ calculation of conventional water demands of WUU } \\
\hline & & j & \multicolumn{2}{|r|}{ evaluation of water sources, (external and local) } \\
\hline & & $\mathrm{k}$ & \multicolumn{2}{|r|}{$\begin{array}{l}\text { optimization of water systems of WUU (including all system } \\
\text { options) }\end{array}$} \\
\hline & & & \multicolumn{2}{|c|}{ Water Utilization Cell (WUC) } \\
\hline & & & & evalt \\
\hline & & & & $\begin{array}{l}\text { if small size, then skip it from planning process of UD or } \\
\text { WUU } \\
\text { if big size, then optimize water system, return results to } \\
\text { UD or WUU }\end{array}$ \\
\hline & $\mathrm{n}$ & \multicolumn{3}{|c|}{$\begin{array}{l}\text { sum water systems of WUU and WUC, compare it with system } \\
\text { plans of UD }\end{array}$} \\
\hline & $\mathrm{o}$ & \multicolumn{3}{|c|}{$\begin{array}{l}\text { if summation match the design of UD, go to next step } \\
\text { if they are not match, go to step } \mathbf{f}\end{array}$} \\
\hline & $\mathrm{p}_{1}$ & \multicolumn{3}{|c|}{ output optimized water system options of UD } \\
\hline$q$ & \multicolumn{4}{|c|}{ sum water systems of UD, construct system plan of UD } \\
\hline $\mathrm{r}$ & \multicolumn{4}{|c|}{ confirm rationality and scales of centralized waterworks and WWTP } \\
\hline & \multicolumn{4}{|c|}{ output optimized integrated urban water system (IUWS) } \\
\hline
\end{tabular}




\section{City capacity vs. water capacity}

As a basic subsystem of the whole city, the urban water system stays in the subordinate position and it is generally planned after the whole city master planning. However, due to limited local natural resources, water scarcity often becomes the bottleneck of city development. If urban water shortage happens, an inestimable price has to be paid for the compensation of water.

Therefore, the city should be planned according to the local environmental capacity, but not the local political will. It might be argued that diverting water from one region to another can be the solution and has been implemented in many cities. Putting its extremely high costs aside, even its influence on the environment is still not clear for us.

Let us briefly look at the case of Beijing city. After many modifications of the local river system, local water resources can sufficiently supply about one million residents, which were also kept for about 500 years. Since the beginning of the last century, the population of Beijing city has dramatically expanded. Up until 2005, Beijing city has held a resident population about 12.8 million [5]. Meanwhile, although Beijing is the political centre of China, it also has many industries. Now it is one of the thirstiest cities all over the world. Unbearable environmental pressures have already compelled the factory of Beijing Capital Steel to remove to another province [6]. It just hits the deep-seated issue, i.e. how could the city planners (or decision makers) identify and plan our city followed by the question that how could they allocate our limited resources.

\section{Conclusion}

All in all, a simple unitary system is not suitable any more, it will be superseded in favour of capable IUWS. In principle, precious water sources should be utilized in more effective and efficient ways. Meanwhile, our artificial systems should be infinitely close to natural system in the sense of both their forms and content. Because of the cycle, our world can go endlessly. Since the beginning of the world, nature has always helped us to close the cycle. Due to today's situation and the development tendency, we are exceeding the environmental capacity. Therefore, we need to find a better way to construct our cities further. This article presents new concepts and methods to rethink and redesign our urban water systems, where the ground philosophy is to close the water cycles in the proper positions in the proper scopes, just as nature does.

\section{Reference}

[1] Frontius, S.J., The Two Books on the Water Supply for the City of Rome, AD97, translated by Clemens Herschel, republished by the New England Water Works Association, Boston, 1973.

[2] Feng, Y., Wichmann, K. \& Otterpohl, R., New Concept and Model of Modern Urban Water System. Proc. of the $2^{\text {nd }}$ Asia-Pacific Regional Group Conference \& Exhibition, Nov. 2007, Perth, Australia. 
[3] GTZ, www.gtz.de/ecosan/

[4] Otterpohl, R., Braun, U., \& Oldenburg, M., Innovative technologies for decentralised wastewater management in urban and peri-urban areas. Keynote presentation at IWA Small2002, Sep. 2002, Istanbul, Turkey

[5] National Bureau of Statistics of China, (in Chinese) www.stats.gov.cn/tjgb/rkpcgb/dfrkpcgb/t20060317_402311329.htm

[6] Xinhuanet, (in Chinese) www.bj.xinhuanet.com/bjpd-zhuanti/sg-sgbq.htm 